\title{
Proposal of Decision-making Model Using the DeLone and McLean's Information System Success Model Together with the AHP
}

\author{
Radek Němec $^{\star}$, František Zapletal ${ }^{\star}$
}

\begin{abstract}
The focus of the paper is to present an evaluation of a proposed decision-making model concept. The concept takes into account the quality of a currently used information system's subsystem (the Business Intelligence subsystem in our case), as it is perceived by its current users. The Analytic Hierarchy Process (AHP) multi-criteria decision making method is used to support the concept with a hierarchical decision criteria structuring framework. A selected part of the DeLone and McLean's (D\&M) information system success assessment model is used for the determination of appropriate criteria (success factors). The D\&M model is composed of information system quality assessment dimensions. These dimensions represent a solid base for surveying information system's users according to their perception of key information system performance aspects. The presented model helps to combine opinions of the management and users successfully when carrying out important information system related decision. The results also illustrate the possibility of using the D\&M model in a novel application together with the AHP method.
\end{abstract}

Keywords: Analytic Hierarchy Process, DeLone \& McLean's model, success factors, multicriteria decision-making, decision-making model, evaluation through case study.

\section{Introduction}

Business Intelligence (BI) system is a key part of nearly every complex information system in many enterprises in the world. As a critical information system component it provides computerized decision-making process support for all levels of management. Every BI system is a subject to frequent changes in the systems' architecture and data structures in order to maintain it in a state of full recency, see Turban et al. (2007). Responsible management of changes in the BI system requires rigorous analysis of changes impact by means of a specific evaluation framework that takes into account also the system performance. Such evaluation framework should acquire practically and also scientifically approved quality and economic metrics to be complex and enterprise-widely usable. From the user point of view, the quality of information system is usually characterized by flexibility, effectiveness, accessibility and timeliness of output metrics that are measured mainly on the system's component level but also on the system level, see Stair and Reynolds (2010). Perception of these quality metrics by users indicates whether the system is designed according to users' requirements. We can

\footnotetext{
* Department of Systems Engineering, Faculty of Economics, Technical University of Ostrava,

Sokolská tř. 33, 701 21, Ostrava 1, Czech Republic

$\bowtie$ radek.nemec@vsb.cz,frantisek.zapletal@vsb.cz
} 
therefore assume that such perception can be used as a source for the definition of criteria in making decisions about changes in the information system or a selected part. A level of agreement of the user with these quality factors can then be a source of data for the evaluation of possible options of eventual system improvement.

From a holistic point of view, the quality of information system affects also the performance of business processes. This fact is emphasized by the fact that workflow task execution commonly spans multiple departments and business roles, see Hočevar and Jaklič (2010). A poorly and user unfriendly designed information system can degrade business process workflow performance. The business value addition of tasks executed by employees that usually need to use the information system's interfaces to complete their tasks should not be taken lightly, see Duggan and Reichgelt (2006). A degree of user requirement meeting failure is also a crucial metric for the determination of whether the information system or its component should be replaced, or significantly improved. The aforementioned perception of its qualities (i.e. quality factors) by its users is therefore a vital source of information.

In this paper, we propose a decision-making model based on the application of the analytic hierarchy process (AHP) method to determine a best possible option of whether to replace the information system's BI component, improve it or possibly leave the system in its current state. The results may illustrate novel application of the DeLone and McLean's model together with the AHP decision-making method which should be in close accordance with the hierarchical concept of the D\&M model.

The evaluation of the decision-making model is carried out using data we gathered during studying a specific decision-making situation in a certain Czech firm that wanted to assess sources of low performance of their currently used BI system. The decision making criteria hierarchy is chosen according to the structure of a selected part of the DeLone and McLean's information system success assessment model. The DeLone and McLean's model served as a framework for designing survey questions that focused on assessment of success factors linked with specific characteristics of the BI system. The respondent's answers were then used to calculate preferences of each criterion and subcriteria.

The paper is divided into 4 chapters. Chapter 2 deals with the analysis of input data and description of the methodology. In the chapter 3 there is the proposed decision making model described and chapter 4 deals with the evaluation of the model through a case study. Chapter 5 concludes the results and indicates possible further research activities.

\section{Paper methodology and input data}

In the paper, there will be 2 methods used. Besides the AHP method that is a key method of our decision-making model also the exploratory factor analysis (EFA) method is used. The EFA method is used to reduce dimensionality of the original input variables' set and to create more coherent constructs that will be used for construction of criteria (according to the Cronbach's Alpha metric computation), see Costello and Osborne (2005).. The main reason for using the AHP is to ensure the consistency of pairwise comparisons due to the higher number of criteria included. Also the hierarchical concept of the AHP method corresponds with the hierarchical concept of the D\&M model.

To determine the criteria weights we used empirical data gathered during surveying 62 users - mostly middle and operational managers, analysts and also several specialized administrative workers. All surveyed persons were users of the BI system's tools in a Czech medium enterprise. Attitudes to and opinions on respective factors of 7 dimensions of BI 
system success (according to the structure of the DeLone and McLean model) were gathered and served as the core data sample. During the data gathering process, the respondents were familiarized with the hierarchy of the model. Respondents evaluated each related success factor on a 6 point Likert scale (where 1 presented lowest and 6 highest level of agreement with, or preference of a respective success factor). The data we gathered in the survey was therefore of a qualitative ordinal type.

Then we wanted to determine whether input variables (see table 13 in the Appendix) that are supposed to represent each success dimension belong consistently to it. Our intention was to ensure that there are no severe inconsistencies due to possible heterogeneity of respondents' opinions (so that the evaluation of the model can be considered reliable). We utilized computation of Cronbach's Alpha coefficient $(\alpha)$ of the input data that measures the overall correlation between variables that are meant to measure the same fact (i.e. the dimensions of success, in terms of this paper's focus), see Wixom and Todd (2005). The condition of sufficient consistency in terms of the coefficient's value is if $\alpha \geq 0.7$ (resulting computed coefficient values are summed up later in the text). EFA and Cronbach's Alpha coefficient related computations were done using the IBM SPSS 20 software.

\subsection{Brief description of the AHP method}

Saaty (2005) describes the AHP as one of multi-criteria decision-making methods which are based on layering a complex decision-making problem or planning situation into its components or levels and their structuring into an ascending hierarchy. Components of one level are connected to components of a lower level and hierarchy levels are herewith integrated towards the decision-making goal. The method is especially helpful in a situation where there is an explicit need to carry out a decision according to the opinions of a group of decision-makers (i.e. it allows the use of group thinking).

Principally, the AHP method is based on assigning preferences to variants and criteria for the assessment of variants. The preference of criteria is determined using pairwise comparison using a specific numeric measurement on a prescribed scale, commonly using Saaty's matrices. Saaty's matrices are constructed according to the fact that values should express the importance towards a goal of the decision-making process, see Saaty and Vargas (2001). The preferences of each variant are then determined based on its interaction with each criterion (and the pairwise comparison of preferences for each alternative). Afterwards there are weights of each criterion set and the total preference of each variant is then calculated according to how they contribute to the fulfillment of the goal.

The AHP hierarchy based decision-making method found its various uses in many fields due to its flexibility and universality, e.g. allocation of resources, benchmarking, quality management, conflict solving or classification of buildings according to their historical importance etc., see e.g. Forman and Saul (2001). For other original applications of the AHP method in various situations and frameworks see e.g. Wei (2007), Karaarlsan and Gundogar (2008), Razavi, Aliee and Badie (2010) or Ergu et al. (2011).

\subsection{Description of the DeLone \& McLean's information system success assessment model}

DeLone \& McLean's (D\&M) information system success assessment model, as presented in Delone and McLean (2003) is a theoretical concept of user satisfaction assessment using 7 success dimensions. Each dimension can be characterized by a set of success factors, although DeLone and McLean do not specify by default which factors each of the dimensions should 
contain. The actual user of the model is then free to fill the dimensions with respective factors, according to the desired purpose of the model. The only constraint is that the factors should correspond with the fundamental meaning of the dimension. Figure 1 shows the structure of relations between all of the model dimensions. When considering what factors to use to represent each dimension by its purpose, there are various assumptions and empirical aspects to consider (as stated by the authors that already assessed the model theoretically and practically).

The system quality dimension is, according to Delone and McLean $(2003,2004)$ and Chen and Cheng (2009), intended to measure technical (functional) success - proposed factors are commonly reliability, responsiveness, flexibility; Wixom and Todd (2005) also add accessibility and integration to the list; Shin (2003) adds also system throughput.

The information quality dimension, according to Chen and Cheng (2009), Nelson, Todd and Wixom (2005) and Delone and McLean (2003), measures certain semantic success - factors commonly used are accuracy, currency, relevance, completeness and consistency/understandability of information outputs.

The service quality dimension, in works Delone and McLean (2003, 2004) and Wu and Wang (2006), reflects the importance of services and support in a successful information system - therefore they mention factors as reliability of service, efficiency of service staff or expertise of service staff and also whether the users were involved in the design and implementation process.

Intention to use (which is seen as an attitude to use the system as it is) and use dimension (which should measure to what extent the system is really used) are referred to as closely interrelated dimensions that are to be considered carefully. The reason is because of different attitudes of users to what the same system literally should really do and what it currently does depending on the users' job position, see Wu and Wang (2006).

The user satisfaction dimension measures if the user is satisfied with the system as a whole and therefore it is determined by system, information and service quality, see $\mathrm{Wu}$ and Wang (2006) or Chen and Cheng (2009).

The net benefits dimension, according to Delone and McLean (2003), previously featured individual and organizational benefits (in a 1992 version of the D\&M IS success model). After revision of the model in 2003, the net benefits dimension is in fact intended to measure overall effectiveness of the system usage. DeLone and McLean admit assessment using common financial measures (e.g. Total Cost of Ownership or Return on Investments, etc.) but $\mathrm{Wu}$ and Wang (2006) rather emphasize assessment of net benefits. The intention is to mainly use this dimension as an abstract/qualitative measure (financial measures are too dependent on the current situation when the model is applied). Particular factors proposed in Delone and McLean (2003) for the net benefits dimension include:

- perceived task productivity,

- task innovation,

- customer satisfaction and management control (expression of the extent to which the application helps to regulate and support business processes and their performance). 


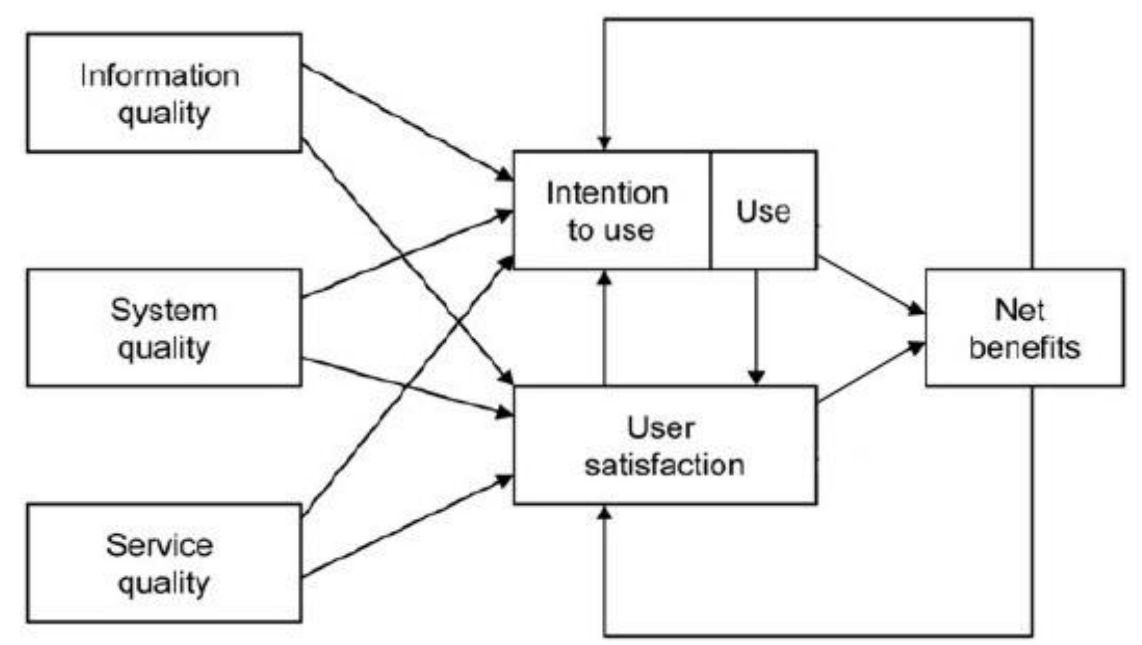

Fig. 1. Updated DeLone and McLean information system success model (Delone and McLean, 2003).

\section{The decision making model concept}

For the purpose of the decision-making concept evaluation and validation we initially chose a selected part of the DeLone \& McLean's model that represents the relationship between information quality (quality of information outputs - timeliness, accuracy, format, etc.), system quality (quality of system characteristics - system performance and flexibility, accessibility etc.) and service quality (supporting services, training, technical support, etc.) and total user satisfaction. Similar criteria in terms of an information system success are used in Yeoh (2010), Barclay (2008) or Delone and McLean (2003). This part of the model was selected due to a fact that the first 3 dimensions and their relationship to overall user satisfaction usually serve as first instance indicators of quality that can be directly assessed by information system's users (as mentioned in the chapter 1). So the users can tell if an information technology, which is intended to be used enterprise-wide, does or does not support the effective execution of business processes (and therefore successful fulfillment of business goals).

Selected dimensions of BI system success were represented by a variable amount of detailed success factors (survey questions) in our research. However, aforementioned authors, concerned with the application or evaluation of DeLone and McLean's model, have been using more coherent sets of success factors (2 to 4 questions).

Therefore, we applied the EFA method using principal component analysis to determine whether the groups of success factors are related or not (see table 13 in the Appendix for the original set of variables that was used in the EFA), see Costello and Osborne (2005). To ensure that resulting factor groups will not be correlated, we applied the Varimax rotation method. Factor loadings of each variable should be $\geq 0.5$, eigenvalue $>1$ and communality of each variable should not be $<0.5$ to maintain adequate advisability of obtaining factor model components, see Kaiser (1958). See table 1 for the results of the factor analysis that satisfied these conditions. To test whether the data sample fits each factor model (set of uncorrelated variables) we run the KMO test (Kaiser-Meyer-Olkin's) on each set of variables representing a specific dimension. Sample fitness was determined to be significant at a $p<0.01$ level for each dimension using the Bartlett's test of sphericity.

Regarding the Cronbach's $\alpha$ coefficient, the information quality dimension exhibited $\alpha=0.76$, the system quality dimension exhibited $\alpha=0.88$ and the service quality exhibited $\alpha=0.82$. All values of internal consistency were over the desired threshold of $\alpha \geq 0.7$ so, in accordance 
with the results of Wixom and Todd (2005), we cannot guarantee that the survey respondents provided answers homogeneous enough. So there should be no severe inconsistencies in terms of high inter-dimensional variable correlations.

\section{Evaluation of the proposed decision-making model concept through a case study}

The proposed concept's evaluation will be illustrated on a decision-making situation when a certain Czech company wanted to make a decision on what to do with their current BI system. The system was not performing very well and the software provider no longer existed. The management came up with several options and the project team was tasked to carry out a survey among key users and then perform necessary analyses. The focus was therefore to determine which of these variants will be more preferred if user and management's opinion is combined with the evaluation of available variants:

- to build a new BI system in-house (NEW_IH),

- to buy a new BI system from a new vendor (NEW_V),

- to alter the current BI system using in-house capacities (ALTER),

- to make no changes and continue to use the current system (NO_CH).

\begin{tabular}{|c|c|c|}
\hline Dimension & $\begin{array}{l}\text { Success factor groups (obtained as factor model } \\
\text { components) }\end{array}$ & $\begin{array}{l}\text { Factor } \\
\text { code }\end{array}$ \\
\hline Information quality & Relevance, accuracy a format & InfQ1 \\
\hline $\begin{array}{l}\text { (previously } 7 \\
\text { variables) }\end{array}$ & Co & \\
\hline$K M O=0.733$ & & \\
\hline System quality & $\begin{array}{l}\text { Reliability, flexibility, system performance, data quality } \\
\text { and structure }\end{array}$ & SysQ1 \\
\hline (previously 14 & Security and existence of metadata & SysQ2 \\
\hline & Accessibility and portability & SysQ3 \\
\hline$n$ & Level of source data integration & SysQ4 \\
\hline Service quality & $\begin{array}{l}\text { Reliability and transparency of services, skills of service } \\
\text { teams }\end{array}$ & SerQ1 \\
\hline $\begin{array}{l}\text { (previously } 11 \\
\text { variables) }\end{array}$ & $\begin{array}{l}\text { Quality of communication with service teams, } \\
\text { involvement of users during system changes }\end{array}$ & SerQ2 \\
\hline$K M O=0.794$ & Quality and effectiveness of training services & SerQ3 \\
\hline
\end{tabular}

Tab. 1. Dimensions and grouped success factors obtained from factor analysis. Source: Authors.

First, the structure and hierarchy of success factors (i.e. criteria) to use in the multi-criteria decision-making process was necessary to be defined with respect to the use of the AHP method (see Figure 2). Second, the subcriteria need to be put into Saaty's matrices which are used to describe the power of preferences among particular subcriteria. 


\subsection{Arrangement of Saaty's matrices}

The power of preference is expressed by integer values $1,2, \ldots, 9$ (where $1=$ equality, $3=$ week preference, $5=$ strong preference, $7=$ very strong preference, $9=$ absolute preference; the remaining values express inter-preferences). The scale that was used while gathering the data established boundaries of a closed interval of means to $\langle 3,726 ; 4,645\rangle$ (see table 2).

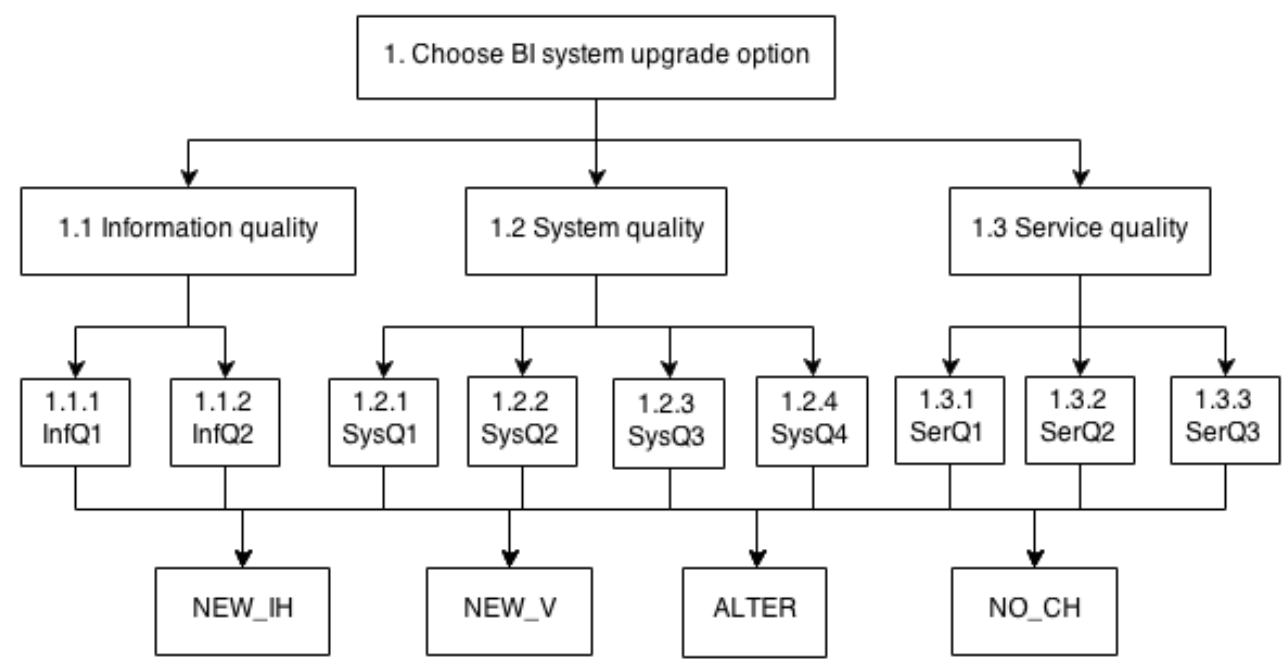

Fig. 2. Hierarchy of criteria and subcriteria (success factors) for the application of the AHP method (subcriteria codes correspond with factor codes in Tab. 1). Source: Authors.

The Saaty's matrix is however originally designed to use a 9 points scale and the data contained only 6 points scale answers, due to previous bad experience with wider scales in the measurement of user preferences in the organization. The data had to be converted to the 9 point scale to be able to use the AHP method. The 9-point scale is beneficial also because of the fact that it can more clearly emphasize differences between levels of preference (also the 9 point scale is generally recommended in Saaty (2005)). Initial data for Saaty's matrices for each criterion at the higher level and for each group of subcriteria was then calculated using simple arithmetic mean.

The Saaty's matrix is symmetric along the main diagonal. Entries on the main diagonal $\left(s_{i, i}\right)$ are equal to 1 and other elements are determined by equation $s_{i, j}=\frac{1}{s_{j, i}}$. The calculation of preferences among particular subcriteria is done by ratio difference (see table 7 in the Appendix; elements denoted as "neg" explain the negative value of the odd). Preferences are then obtained by the differences between means from the table 2 .

All mean differences lie in the interval $\langle 0 ; 0.919\rangle$ (minimum mean value is 3.726 , maximum value is 4.645 ; value range is then 0.919 and the transformation interval threshold value is then 0.102 ) and a maximum of the potential value difference from the interval of the mean is shown in the table 2.

Transformation interval boundaries are shown in the table 3; the equidistant scaling is used for transforming the values in order to keep the ratios between preference powers. This is necessary for keeping the original difference ratios (without regard to the sample distribution). Table 8 (see the Appendix) contains final Saaty's matrices with calculated inverse elements. 
Ratios of particular success factors (criteria) are calculated according to equation 1:

$$
w_{i}=\frac{G A_{i}}{\sum_{i}^{N} G A_{i}},
$$

which is based on the geometrical mean (equation 2):

$$
\mathrm{GA}_{\mathrm{i}}=\left[\prod_{j}^{N} s_{i, j}\right]^{\frac{1}{N}},
$$

where $w_{i}$ is the ratio of the $i$-th factor, $N$ is the number of rows (even columns) of the matrix and $s_{i, j}$ is the element of the Saaty's matrix. Final calculated ratios are shown in tables 9-12 (see the Appendix).

\begin{tabular}{|llc|}
\hline Subcriteria & $\begin{array}{c}\text { Means of } \\
\text { subcriteria }\end{array}$ & $\begin{array}{c}\text { Means } \\
\text { of criteria }\end{array}$ \\
\hline 1.1 .1 & 4.642 & 4.527 \\
1.1 .2 & 4.411 & \\
\hline 1.2 .1 & 4.410 & \\
1.2 .2 & 4.645 & 4.461 \\
1.2 .3 & 4.234 & \\
1.2 .4 & 4.556 & \\
\hline 1.3 .1 & 4.391 & \\
1.3 .2 & 3.726 & 3.985 \\
1.3 .3 & 3.839 & \\
\hline
\end{tabular}

Tab. 2. Means of success factors (subcriteria). Source: Authors.

\begin{tabular}{|llc|}
\hline \multicolumn{2}{|c|}{ Interval } & Matrix value \\
\hline 0 & 0.102 & 1 \\
0.103 & 0.204 & 2 \\
0.205 & 0.306 & 3 \\
0.307 & 0.408 & 4 \\
0.409 & 0.511 & 5 \\
0.512 & 0.613 & 6 \\
0.614 & 0.715 & 7 \\
0.716 & 0.817 & 8 \\
0.818 & 0.919 & 9 \\
\hline
\end{tabular}

Tab. 3. Intervals for the conversion of the original input data to the Saaty's matrix values. Source: Authors. 
The consistency of the Saaty's matrix is a condition for the success factors evaluation relevance. The matrix is consistent whether its consistency ratio (CR) is lower or equal to 0.1 , see Saaty and Vargas (2001) - this ratio is calculated by equation 3.

$$
C R=\frac{C I}{R I}
$$

The equation 4 expresses calculation of a consistency index (CI):

$$
C I=\frac{\lambda_{\max }-n}{n-1},
$$

where $\lambda_{\max }$ is the highest eigenvalue of the Saaty's matrix (eigenvalue results from the equation $\operatorname{det}(A-\lambda E)=0$ ). The random index $(R I)$ is a tabular value which is determined by the count of independent rows in the Saaty's matrix. Consistency ratio values are presented in tables 9-12 in the Appendix. All four mentioned tables indicate that all Saaty's matrices satisfy the consistency condition. This means that results will be relevant in terms of AHP method's constraints.

\subsection{Determination of the order of variants}

Local weights $\left(w_{i}\right)$ at each group are calculated in tables 9-12 (see the Appendix). It is necessary to multiply the weight of $n$-th analyzed success factor by local weights of success factors that are superordinate to this $n$-th success factor in the hierarchy ${ }^{1}$ to obtain global weights (it means the evaluation from the perspective of the whole model structure). Results are presented in table 4 .

The respective management representatives provided also their opinion on all four possible variants also from the same success factor point of view. The resulting preference opinions were compared using simple pairwise Fuller's triangles (as described also by Kampf, 2003) overall preference of each variant was gathered as a sum of the preferences of the variant prior to any other within the scope of each success factor (table 5). Such data can then be combined with results in previously calculated Saaty's matrices. Values from table 5 were then multiplied by local weights of the incident success factor to be able to evaluate variants with regard to success factors weights (gained from Saaty's tables).

The table 6 shows that it was possible to determine exact rank of each variant based on the defined hierarchy of criteria and subcriteria (the proposed decision-making concept yields meaningful results). A dominant variant can be clearly selected according to criteria weights derived from the data. Values for subcriteria are the results of the multiplication of the global weights (table 4) and appropriate numbers of preferences from the table 5. The selected part of the DeLone and McLean's model served as an appropriate and relevant framework for deriving necessary success factors and solving the decision-making situation. Further research and evaluation of the concept in the field of information system quality assessment is however highly desirable. There are usually more success dimensions and measures of overall quality of the information system (including also financial measures or business process performance measures) which can largely enhance the concept - we see it as a next topic for our further research.

\footnotetext{
${ }^{1}$ Whether there are more super ordinate levels in the model, the $n$-th factor weight would be multiplied by all factor weights from each of these levels.
} 
Another possibility of further evaluation of the concept is to use it in a more volatile situation where more advanced concepts like fuzzy AHP or the analytic network process (i.e. using multi-way relationships between dimensions) could be more useful. More possibilities of applying the decision-making model can then viable, like software requirements definition and prioritization.

The Fuzzy AHP approach was studied in Ding (2013) in a logistic decision-making situation. The results of the paper indicate that replacing crisp values with fuzzy alternatives yields better results when dealing with user opinions. It also indicates that the fuzzy related approach is a good choice to think about if the applicability of our approach is to be extended. A theoretical results indicating advantage of the fuzzy AHP method over traditional discrete variant were also presented in Bajaj and Arora (2013). Although the decision-making situation was very narrow in the paper the results show that the overall volatility of human opinion based data is better to be assessed using fuzzy-based method. Similar solutions are covered by another AHP method variant - the incomplete AHP (IAHP).

Our approach is also closer to requirements prioritization since the success factors can be translated easily into requirements and prioritized in an almost same way. Voola and Babu (2013) presented a novel approach (Extensive Numeric Assignment) which is used to prioritize requirements mainly in agile projects which uses a similar framework of criteria. Authors of the mentioned paper compare their solution with results obtained using more traditional methods (including the AHP method). Their approach yielded better results than the AHP method so there is a possibility of replacing the AHP method with Voola and Babu's approach. We wish to evaluate also this solution and compare results in our further research.

\begin{tabular}{|llrr|}
\hline \multicolumn{1}{|c}{ Criteria/sub criteria/goal } & \multicolumn{1}{c}{$\begin{array}{c}\text { Local } \\
(\boldsymbol{\%})\end{array}$} & $\begin{array}{r}\text { Global } \\
(\boldsymbol{\%})\end{array}$ \\
\hline 1. & Goal & 100.00 & - \\
1.1. & Information quality & 47.21 & 47.21 \\
1.2. & System quality & 44.43 & 44.43 \\
1.3. & Service quality & 8.36 & 8.36 \\
1.1.1. & Relevance, accuracy and format & 75.00 & 35.41 \\
1.1.2. & Completeness and recency of outputs & 25.00 & 11.80 \\
1.2.1. & Reliability, flexibility, system performance, data quality and & 16.38 & 7.28 \\
1.2.2. & Structure & & \\
1.2.3. & Accurity and existence of metadata & 40.13 & 17.83 \\
1.2.4. & Level of source data integration & 9.74 & 4.33 \\
1.3.1. & Reliability and transparency of services, skills of service & 33.75 & 14.99 \\
& teams & 72.86 & 6.09 \\
1.3.2. & Quality of communication with service teams, involvement & 16.26 & 1.36 \\
& of users during system changes & & \\
1.3.3. & Quality and effectiveness of training services & 10.88 & 0.91 \\
\hline
\end{tabular}

Tab. 4. Calculated local and global ratios of criteria. Source: Authors. 


\begin{tabular}{|lcccccccccc|}
\hline Criteria & InfQ1 & InfQ2 & SysQ1 & SysQ2 & SysQ3 & SysQ4 & SerQ1 & SerQ2 & SerQ3 \\
\hline NEW_IH & 2 & 2 & 2 & 2 & 3 & 3 & 2 & 3 & 2 \\
NEW_V & 1 & 1 & 0 & 0 & 1 & 1 & 1 & 0 & 0 \\
ALTER & 3 & 3 & 3 & 3 & 2 & 2 & 3 & 2 & 2 \\
NO_CH & 0 & 0 & 1 & 1 & 0 & 0 & 0 & 1 & 2 \\
\hline
\end{tabular}

Tab. 5. Value of variants according to success factor and number of preferences gained by the Fuller's triangles method. Source: Authors.

\begin{tabular}{|lrrrr|}
\hline $\begin{array}{l}\text { Variants } \\
\text { Subcriteria }\end{array}$ & NEW_IH & NEW_V & ALTER & NO_CH \\
\hline InfQ1 & 0.708 & 0.354 & 1.062 & 0.000 \\
InfQ2 & 0.236 & 0.118 & 0.354 & 0.000 \\
SysQ1 & 0.146 & 0.000 & 0.218 & 0.073 \\
SysQ2 & 0.357 & 0.000 & 0.535 & 0.178 \\
SysQ3 & 0.130 & 0.043 & 0.087 & 0.000 \\
SysQ4 & 0.450 & 0.150 & 0.300 & 0.000 \\
SerQ1 & 0.122 & 0.061 & 0.183 & 0.000 \\
SerQ2 & 0.041 & 0.000 & 0.027 & 0.014 \\
SerQ3 & 0.018 & 0.000 & 0.018 & 0.018 \\
\hline Total & 2.207 & 0.726 & 2.784 & 0.283 \\
\% & 73.6 & 24.2 & 92.8 & 9.4 \\
Rank & $\mathbf{2}$ & $\mathbf{3}$ & $\mathbf{1}$ & $\mathbf{4}$ \\
\hline
\end{tabular}

Tab. 6. Final variants' ranks calculated using ratios of subcriteria. Source: Authors.

\section{Conclusion}

The aim of the paper was to present evaluation of a novel decision-making model concept proposal. The model concept that takes into account the quality of currently used information technology (BI system in this case) as perceived by its users. A part of the DeLone and McLean's information system success model was used to arrange the criteria and subcriteria in a hierarchy; every higher level criterion was relative to a specific success dimension and subcriterion to underlying success factors of each dimension. The evaluation of the concept was made in the situation when a certain firm wanted to select one of possible options what to do with their low performing BI system (perception of its quality aspects was taken into account in the decision-making model). The AHP method has been selected to support the model concept from the decision-making support point of view.

According to presented results, the selected part of the DeLone and McLean's model proved to be useful in the proposed decision-making framework. The possible use of the AHP method together with the D\&M model was then illustrated. A dominant variant was 
successfully determined according to final ranks of each variant and based on the included criteria and subcriteria. The proposed combination of the AHP method and the D\&M model can be assumed as theoretically as well as a practically applicable (in terms of the proposed concept). Further evaluation, revision and enrichment of the concept is, however, viable. The reason is that only deterministic, complete-information and have been assumed thus far in the concept. Also, the use of other dimensions of the D\&M model could be considered. That would make the decision-making model concept more complete considering the purpose of the whole D\&M information system success model structure.

\section{Acknowledgements}

This paper was made with the financial support of the European Social Fund within the project CZ.1.07/2.3.00/20.0296 and Student Grant Competition research project SP2012/184 "The analysis of data warehouse's database schema modeling characteristics with a focus on agile approach to Business Intelligence system development".

\section{References}

Bajaj, P., \& Arora, V. (2013) Multi-Person Decision-Making for Requirements Prioritization using Fuzzy AHP. ACM SIGSOFT Software Engineering Notes, 38(5), 1-6. doi: $\underline{10.1145 / 2507288.2507302}$

Barclay, C. (2008) Towards an integrated measurement of IS project performance: The project performance scorecard. Information Systems Frontiers, 10(3), 331-345. doi: 10.1007/s10796$\underline{008-9083-6}$

Costello, A. B., \& Osborne, J. (2005). Best practices in exploratory factor analysis: four recommendations for getting the most from your analysis. Practical Assessment Research \& Evaluation, 10(7). 1-9.

Chen, Ch.-D., \& Cheng, CH.-J. (2009) Understanding consumer intention in online shopping: a respecification and validation of the DeLone and McLean model. Behaviour \& Information Technology, 28(4), 335-345. doi: 10.1080/01449290701850111

DeLone, W. H., \& McLean, E. R. (2004) Measuring Success: Applying the DeLone \& McLean Information Systems Success Model. International Journal of Electronic Commerce, 9(1), 31-47.

DeLone, W. H., \& McLean, E. R. (2003) The DeLone and McLean Model of Information System Success: A Ten-year Update. Journal of Management Information Systems, 19(4), 9-30. doi: $\underline{10.1080 / 07421222.2003}$

Ding, J.-F. (2013) Applying an Integrated Fuzzy MCDM Method to Select Hub Location for Global Shipping Carrier-based Logistics Service Providers. WSEAS Transactions on Information Science and Applications, 10(2), 47-57. doi: 10.1016/j.jclepro.2013.02.010

Duggan, E. W., \& Reichgelt, H. (2006) Measuring information systems delivery quality. Hershey: Idea Group Publishing. doi: $10.2307 / 249419$

Ergu, D., Kou, G., Peng, Y., Shi, Y., \& Shi, Y. (2011) The analytic hierarchy process: task scheduling and resource allocation in cloud computing environment. The Journal of Supercomputing, 59(1), 1-14. doi: $10.1007 / \mathrm{s} 11227-011-0625-1$

Forman, E. H., \& Saul, I. G. (2001) The Analytical Hierarchy Process - An Exposition. Operations Research, 49(4), 469-487.

Hočevar, B., \& Jaklič, J. (2010) Assessing benefits of Business Intelligence systems - A case study. Management, 15(1), 87-119.

Kaiser, H. F. (1958) The Varimax Criterion for Analytic Rotation in Factor Analysis. Psychometrika, 23(3), 187-200. doi: 10.1007/BF02289233 
Kampf, R. (2003) Estimation Methods for Weight Criteria. Scientific Papers of the University of Pardubice: Series B - The Jan Perner Transport Faculty, 9, 255-261.

Karaarslan, N., \& Gundogar, E. (2008) An application for modular capability-based ERP software selection using AHP method. The International Journal of Advanced Manufacturing Technology, 42(9-10), 1025-1033. doi: $10.1007 / \mathrm{s} 00170-008-1522-5$

Nelson, R. R., Todd, P. A., \& Wixom, B. H. (2005) Antecedents of Information and System Quality: An Empirical Examination within the Context of Data Warehousing. Journal of Management Information Systems, 21(4), 199-235. doi: 10.1080/07421222.2005.11045823

Razavi, M., Aliee, F. S., \& Badie, K. (2010) An AHP-based approach toward enterprise architecture analysis based on enterprise architecture quality attributes. Knowledge and Information Systems, 28(2), 449-472. doi: 10.1007/s10115-010-0312-1

Saaty, T. L. (2005) Analytic Hierarchy Process. Encyclopedia of Biostatistics, 2nd ed. New Jersey: John Willey. doi: 10.1002/0470011815.b2a4a002

Saaty, T. L., \& Vargas, L. G. (2001) The Seven Pillars of the Analytic Hierarchy Process. Models, Methods, Concepts \& Applications of the Analytic Hierarchy Process, 34. doi: 10.1007/978-14614-3597-6 2

Saaty, T. L. (1990) How to make a decision: the analytic hierarchy process. European Journal of Operations Research, 48(1), 9-26. doi: 10.1016/0377-2217(90)90057-I

Shin, B. (2003) An Exploratory Investigation of System Success Factors in Data Warehousing. Journal of the Association for Information Systems, 4, 141-170. doi: 10.3233/978-1-61499-289-9$\underline{861}$

Stair, R. M., \& Reynolds, G. W. (2010) Information Systems Essentials, 5th ed. Boston: Course Technology.

Turban, E., Aronson, J. E., Liang, T-P., \& Sharda, R. (2007) Decision support and Business Intelligence systems, 8th ed. New Jersey: Pearson Prentice Hall.

Voola, P., \& Babu, A. V. (2013) Comparison of Requirements Prioritization Techniques Employing Different Scales of Measurement. ACM SIGSOFT Software Engineering Notes, 38(4), 1-10. doi: $\underline{10.1145 / 2492248.2492278}$

Wei, C.-C. (2007) Evaluating the performance of an ERP system based on the knowledge of ERP implementation objectives. The International Journal of Advanced Manufacturing Technology, 39(1-2), 168-181. doi: $10.1007 / \mathrm{s} 00170-007-1189-3$

Wixom, B. H., \& Todd, P. A. (2005) A theoretical integration of user satisfaction and technology acceptance. Information Systems Research, 16(1), 85-102. doi: 10.1287/isre.1050.0042

Wu, J.-H., \& Wang, Y.-M. (2006) Measuring KMS Access: A Respecification of the DeLone and McLean's Model. Information \& Management, 43, 728-739. doi: 10.1016/j.im.2006.05.002

Yeoh, W. (2010) Critical Success Factors for Business Intelligence Systems - Case studies in Engineering Enterprises. Saarbrücken: VDM Verlag. 


\section{Appendix}

\begin{tabular}{|r|l|l|l|l|l|l|l|l|l|l|l|l|l|}
\hline Criteria & Mean & 1.1. & $\mathbf{1 . 2}$ & $\mathbf{1 . 3}$ & $\mathbf{1 . 1 . 1}$ & $\mathbf{1 . 1 . 2}$ & $\mathbf{1 . 2 . 1}$ & $\mathbf{1 . 2 . 2}$ & $\mathbf{1 . 2 . 3}$ & $\mathbf{1 . 2 . 4}$ & $\mathbf{1 . 3 . 1}$ & $\mathbf{1 . 3 . 2}$ & $\mathbf{1 . 3 . 3}$ \\
\hline 1.1. & 4.527 & 0 & 0.065 & 0.541 & & & & & & & & & \\
\hline 1.2. & 4.461 & neg & 0 & 0.476 & & & & & & & & & \\
\hline 1.3. & 3.985 & neg & neg & 0 & & & & & & & & & \\
\hline 1.1.1. & 4.642 & & & & 0 & 0.231 & & & & & & & \\
\hline 1.1.2. & 4.411 & & & & neg & 0 & & & & & & & \\
\hline 1.2.1. & 4.410 & & & & & & 0 & neg & 0.176 & neg & & & \\
\hline 1.2.2. & 4.645 & & & & & & 0.235 & 0 & 0.411 & 0.089 & & & \\
\hline 1.2.3. & 4.234 & & & & & & neg & neg & 0 & neg & & & \\
\hline 1.2.4. & 4.556 & & & & & & 0.146 & neg & 0.322 & 0 & & & \\
\hline 1.3.1. & 4.391 & & & & & & & & & & 0 & 0.612 & 0.508 \\
\hline 1.3.2. & 3.726 & & & & & & & & & & neg & 0 & neg \\
\hline 1.3.3. & 3.839 & & & & & & & & & & neg & 0.113 & 0 \\
\hline
\end{tabular}

Tab. 7. The indication of factor preferences differences. Source: Authors.

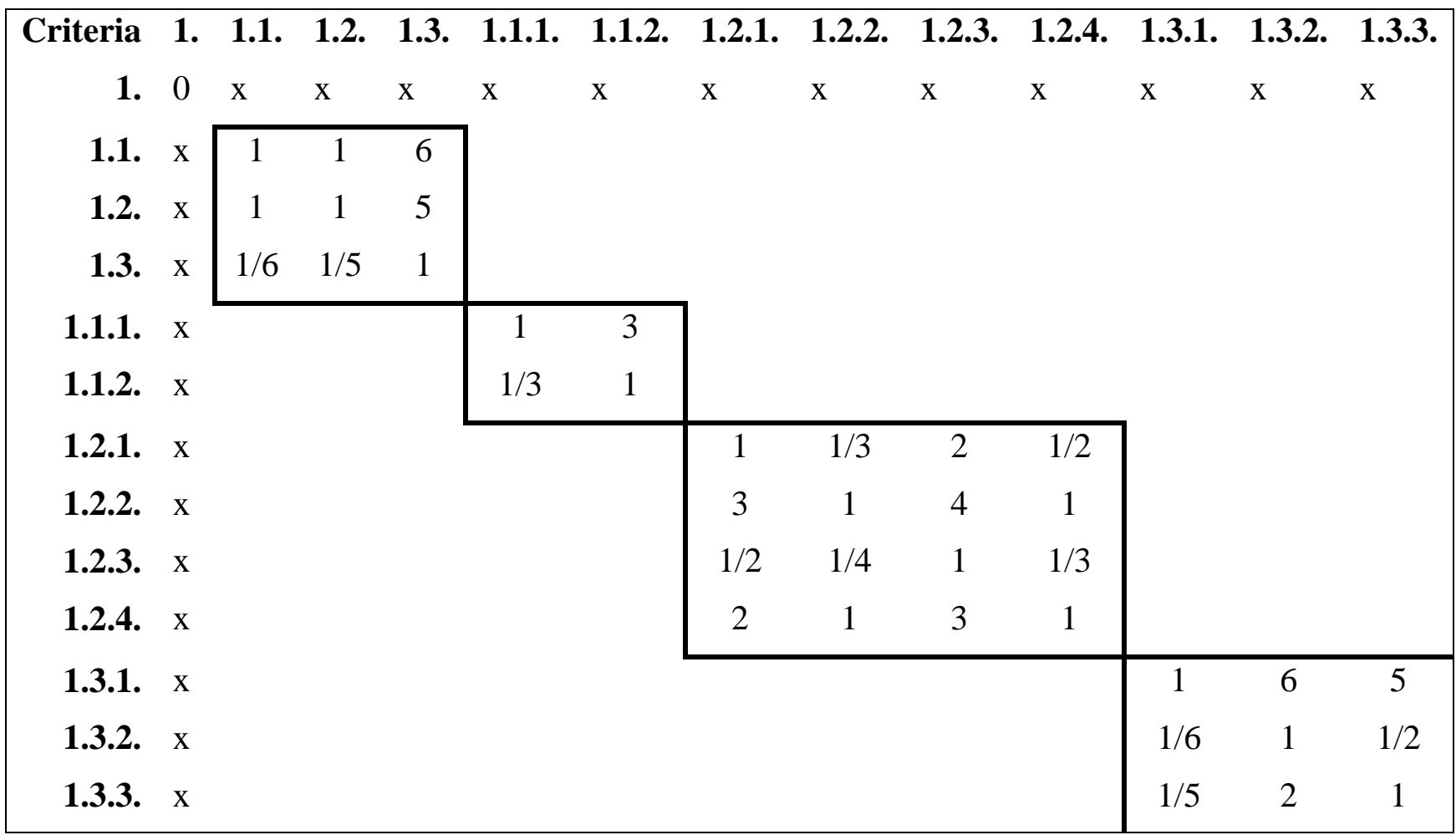

Tab. 8. Calculated Saaty's matrix. Source: Authors. 


\begin{tabular}{|llllrl|}
\hline & \multicolumn{1}{c}{$\mathbf{1 . 1 .}$} & $\mathbf{1 . 2}$ & $\mathbf{1 . 3}$ & $\mathbf{G A}$ & $\boldsymbol{w}(\boldsymbol{i})$ \\
1.1. & 1 & 1 & 6 & 1.81712 & 0.47211 \\
1.2. & 1 & 1 & 5 & 1.70998 & 0.44427 \\
1.3. & 0.16667 & 0.2 & 1 & 0.32183 & 0.08362 \\
$\lambda_{\max }=$ & $\mathbf{3 . 0 0 3 7}$ & & $\sum$ & $\mathbf{3 . 8 4 8 9 3}$ & $\mathbf{1}$ \\
$\mathbf{C I}=$ & $\mathbf{0 . 0 0 1 8 5}$ & & & $\mathbf{R I}=\mathbf{0 . 5 8}$ \\
$\mathbf{C R}=$ & $\mathbf{0 . 0 0 3 1 8}$ & & & $\mathbf{N}=\mathbf{3}$ \\
\hline
\end{tabular}

Tab. 9. Calculated Saaty's matrix for the goal. Source: Authors.

\begin{tabular}{|lllrl|}
\hline & 1.1.1. & 1.1.2. & GA & $w(\boldsymbol{i})$ \\
1.1.1. & 1 & 3 & 1.73205 & 0.75 \\
1.1.2. & 0.33333 & 1 & 0.57735 & 0.25 \\
$\lambda_{\max }$ & $=\mathbf{2}$ & $\sum$ & $\mathbf{2 . 3 0 9 4}$ & $\mathbf{1}$ \\
$\mathbf{C I}$ & $=\mathbf{0}$ & & $\mathbf{R I}=\mathbf{0}$ \\
$\mathbf{C R}$ & $=\mathbf{0}$ & & $\mathbf{N}=\mathbf{2}$ \\
\hline
\end{tabular}

Tab. 10. Calculated Saaty's matrix for the information quality dimension. Source: Authors.

\begin{tabular}{|l|l|l|l|l|c|l|}
\hline & 1.2.1. & 1.2.2. & 1.2.3. & $\mathbf{1 . 2 . 4}$ & GA & $w(i)$ \\
\hline 1.2.1. & 1 & 0.33333 & 2 & 0.5 & 0.75984 & 0.16383 \\
\hline 1.2.2. & 3 & 1 & 4 & 1 & 1.86121 & 0.40130 \\
\hline 1.2.3. & 0.5 & 0.25 & 1 & 0.33333 & 0.45180 & 0.09741 \\
\hline 1.2.4. & 2 & 1 & 3 & 1 & 1.56508 & 0.33745 \\
\hline$\lambda_{\max }=\mathbf{4 . 0 3 0 9 8}$ & & $\sum$ & $\mathbf{4 . 6 3 7 9 3}$ & $\mathbf{1}$ \\
\hline CI $=\mathbf{0 . 0 1 0 3 3}$ & $\mathbf{R I}=\mathbf{0 . 9}$ \\
\hline CR $=\mathbf{0 . 0 1 1 4 7 4 0 7 4}$ & $\mathbf{N}=\mathbf{4}$ \\
\hline
\end{tabular}

Tab. 11. Calculated Saaty's matrix for the system quality dimension. Source: Authors. 


\begin{tabular}{|llllll|}
\hline & $\mathbf{1 . 3 . 1}$ & $\mathbf{1 . 3 . 2}$. & $\mathbf{1 . 3 . 3}$ & $\mathbf{G A}$ & $\boldsymbol{w}(\boldsymbol{i})$ \\
1.3.1. & 1 & 6 & 5 & 3.10723 & 0.72858 \\
1.3.2. & 0.16667 & 1 & 2 & 0.69336 & 0.16258 \\
1.3.3. & 0.2 & 0.5 & 1 & 0.46416 & 0.10884 \\
$\lambda_{\max }=$ & $\mathbf{3 . 0 2 9 0 6}$ & & $\sum$ & $\mathbf{4 . 2 6 4 7 5}$ & $\mathbf{1}$ \\
$\mathbf{C I}=$ & $\mathbf{0 . 0 1 4 5 3}$ & & & $\mathbf{R I}=\mathbf{0 . 5 8}$ \\
$\mathbf{C R}=$ & $\mathbf{0 . 0 2 5 0 5 1 7 2 4}$ & & $\mathbf{N}=\mathbf{3}$ \\
\hline
\end{tabular}

Tab. 12. Calculated Saaty's matrix for the service quality dimension. Source: Authors.

Infq_1: Is the presented information relevant to your job's needs?

Infq_2: Is the acquired information relevant generally towards needs of managing operational processes of organization?

Infq_3: Is the desired information clearly formulated?

Infq_4: Is the information comprehensibly presented on screen and properly formatted?

Infq_5: Do currently used BI tools produce accurate information?

Infq_6: Do currently used BI tools offer all the information you generally need do fulfill your job's tasks?

Infq_7: Do currently used BI tools offer timely information all the time?

Sysq_1: Is the performance of the BI tools satisfactory?

Sysq_2: Do currently used BI tools offer possibility to see the information in appropriate detail?

Sysq_3: Are currently used BI tools flexible enough to satisfy new business requirements and new business conditions?

Sysq_4: Do currently used BI tools react to commands, queries and requirements entered in suitable time period?

Sysq_5: Is the information gained from the system based on quality data?

Sysq_6: Is the systems performance reliable without severe outages?

Sysq_7: Can you easily find data that you need to fulfill your job's tasks?

Sysq_8: Are currently used BI tools appropriately secured against information abuse?

Sysq_9: Do currently used BI tools allow you to gain explanatory or complementary context?

Sysq_10: Is the information available according to transparent system of access authorization?

Sysq_11: Is the information available at the time it is needed?

Sysq_12: Are currently used BI tools available using Internet or Intranet?

Sysq_13: Is the data from different parts of organization effectively combined so that it adds 
value to your job's tasks fulfillment?

Sysq_14: Do currently used BI tools contain information on parts of the organization that were not easily accessible in earlier periods?

Serq_1: Are the services associated with the operation of BI tools provided quickly enough?

Serq_2: Are the services associated with the operation of BI tools provided in adequate quality?

Serq_3: Are the services provided transparently?

Serq_4: Are service teams usually able to settle down problems associated with the operation of BI tools?

Serq_5: Are you allowed to participate on changes in BI tools as a user?

Serq_6: Is your presence as a user required while making changes in BI tools?

Serq_7: Is the communication with the BI tools changes realization team effective enough?

Serq_8: Are the reason for changes explained sufficiently ahead of?

Serq_9: Are there BI tools usage training sessions arranged on a regular basis?

Serq_10: Do trainings include relevant and timely changes in BI tools?

Serq_11: Are trainings an asset to your everyday job's tasks fulfillment?

Tab. 13. The description of original variables that are the source of data for the exploratory factor analysis. Source: Authors. 
